\title{
G6PD testing in support of treatment and elimination of malaria: recommendations for evaluation of G6PD tests
}

\author{
Gonzalo J Domingo ${ }^{1 *}$, Ari Winasti Satyagraha ${ }^{2}$, Anup Anvikar ${ }^{3}$, Kevin Baird $^{4}$, Germana Bancone $^{5}$, Pooja Bansil ${ }^{1}$, \\ Nick Carter ${ }^{6}$, Qin Cheng ${ }^{7}$, Janice Culpepper ${ }^{8}$, Chi Eziefula ${ }^{9}$, Mark Fukuda ${ }^{10}$, Justin Green ${ }^{6}$, Jimee Hwang ${ }^{11}$, \\ Marcus Lacerda ${ }^{12}$, Sarah McGray ${ }^{1}$, Didier Menard ${ }^{13}$, Francois Nosten ${ }^{5,14}$, Issarang Nuchprayoon ${ }^{15}$, Nwe Nwe Oo ${ }^{16}$, \\ Pongwit Bualombai ${ }^{17}$, Wadchara Pumpradit ${ }^{18}$, Kun Qian ${ }^{1}$, Judith Recht ${ }^{14}$, Arantxa Roca ${ }^{19}$, Wichai Satimai ${ }^{20}$, \\ Siv Sovannaroth ${ }^{21}$, Lasse S Vestergaard ${ }^{22}$ and Lorenz Von Seidlein ${ }^{23}$
}

\begin{abstract}
Malaria elimination will be possible only with serious attempts to address asymptomatic infection and chronic infection by both Plasmodium falciparum and Plasmodium vivax. Currently available drugs that can completely clear a human of P. vivax (known as "radical cure"), and that can reduce transmission of malaria parasites, are those in the 8-aminoquinoline drug family, such as primaquine. Unfortunately, people with glucose-6-phosphate dehydrogenase (G6PD) deficiency risk having severe adverse reactions if exposed to these drugs at certain doses. G6PD deficiency is the most common human enzyme defect, affecting approximately 400 million people worldwide.

Scaling up radical cure regimens will require testing for G6PD deficiency, at two levels: 1) the individual level to ensure safe case management, and 2) the population level to understand the risk in the local population to guide Plasmodium vivax treatment policy. Several technical and operational knowledge gaps must be addressed to expand access to G6PD deficiency testing and to ensure that a patient's G6PD status is known before deciding to administer an 8-aminoquinoline-based drug.

In this report from a stakeholder meeting held in Thailand on October 4 and 5, 2012, G6PD testing in support of radical cure is discussed in detail. The focus is on challenges to the development and evaluation of G6PD diagnostic tests, and on challenges related to the operational aspects of implementing G6PD testing in support of radical cure. The report also describes recommendations for evaluation of diagnostic tests for G6PD deficiency in support of radical cure.
\end{abstract}

\section{Goals of the G6PD workshop}

In October 2012, a workshop in Bangkok, Thailand, brought together researchers, diagnostic test developers, drug developers, National Malaria Control Programme (NMCP) representatives, development partners and donors to discuss priority issues related to malaria treatment [1]. The workshop built upon two previous meetings: a March 2012 meeting in London on the rationale for short-course primaquine in Africa to interrupt malaria transmission [2] and a May 2012 workshop on glucose6-phosphate dehydrogenase (G6PD) deficiency that was held in South Korea as part of the Asia Pacific Malaria

\footnotetext{
* Correspondence: gdomingo@path.org

'PATH, 2201 Westlake Avenue, Suite 200, Seattle, WA 98121, USA

Full list of author information is available at the end of the article
}

Elimination Network Vivax Working Group annual meeting [3,4]. The Bangkok workshop provided a forum for discussing the knowledge gaps, barriers, and research questions that must be addressed to support broader availability, adoption, and access to G6PD testing in support of radical cure of Plasmodium vivax.

The goals of the Bangkok workshop were to:

1. Identify technical research priorities to support development of appropriate G6PD testing technologies and strategies in support of $\mathrm{P}$. vivax radical cure.

2. Define use case scenarios or malaria treatment-seeking behaviours that a G6PD test or test result must support. 
3. Identify operational research priorities to support implementation of appropriate G6PD testing technologies and strategies.

Primaquine can be used at low doses as a malaria gametocytocidal to block the transmission of the parasite to the mosquito, or it can be used at higher doses in longer regimens for radical cure of $\mathrm{P}$. vivax infection. The workshop focused on the use of G6PD testing in support of radical cure. The agenda and selected presentations are available online [1].

\section{Background and context}

G6PD deficiency is the most common human enzyme defect, affecting more than 400 million people worldwide [5]. Several recent reviews have explored the relationship between malaria and G6PD deficiency [4,6-8]. The meeting focused on topics relevant to developing and evaluating in vitro diagnostic tests for G6PD activity.

\section{Glucose-6-phosphate dehydrogenase}

G6PD is a critical housekeeping enzyme in red blood cells that supports protective systems against oxidative challenge by producing the reduced form of nicotinamide adenine dinucleotide phosphate (NADPH). The gene for the G6PD enzyme is spread over $18.5 \mathrm{~Kb}$ and 13 exons on the $\mathrm{X}$ chromosome and encodes for a $59 \mathrm{KDa}$ polypeptide. The enzyme is active as a dimer or dimer of dimers configuration. G6PD deficiency is manifested in people with reduced levels of intra-erythrocyte G6PD activity arising typically from mutations in the G6PD gene that impact the stability of the enzyme.

Results from several studies suggest that G6PD deficiency may confer some protection not only against severe malaria but also against non-severe disease [9-11]. Indeed, G6PD deficiency prevalence overlaps significantly with current and historical malaria endemicity [12]. Within these populations, the protection conferred by G6PD deficiency may result in a reduced prevalence of G6PD deficiency among malarial patients as compared to the general population [9-11].

\section{Definition of G6PD activity}

One International Unit (U) is the amount of G6PD activity that will convert 1 micromole of NADP + per minute under predetermined substrate and reaction conditions [13]. Activity may be expressed in either a standard number of cells $\left(\mathrm{U} / 10^{12}\right.$ red blood cells) or amount of haemoglobin $(\mathrm{U} / \mathrm{g} \mathrm{Hb})$. G6PD activity is typically determined by measuring G6PD activity in lysate from a whole blood specimen or a red blood cell preparation from a specimen. G6PD deficiency is defined as a less-thannormal level of G6PD enzyme activity in a blood specimen.
Almost 400 allelic variants in the G6PD gene have been recorded $[8,14,15]$. The variants known to result in G6PD deficiency tend to affect the stability of the enzyme rather than the catalytic activity of the enzyme $[7,8,14,15]$. G6PD variants are categorized based on the severity of the G6PD deficiency they cause. Class 1 variants cause congenital non-spherocytic haemolytic anaemia. Class 2 variants cause severe enzyme deficiency (less than $10 \%$ of normal). Class 3 variants cause moderate to mild enzyme deficiency ( $10 \%$ to $60 \%$ of normal). Class 4 variants cause very mild or no enzyme deficiency (60\% to $100 \%$ of normal) $[13,16]$. How these activity ranges relate to safety of exposure to 8-aminoquinolines is not very clear, nor is the definition of normal, as discussed below.

\section{8-aminoquinolines, malaria, and G6PD deficiency}

Primaquine, an 8-aminoquinoline-based drug, is the only available drug recommended by the World Health Organization (WHO) for radical cure of $\mathrm{P}$. vivax infection. The next most advanced product for radical cure is tafenoquine, which recently completed phase 2 clinical trials.

As a radical cure, primaquine is currently used either in a 7 or 14 day regimen in a doses ranging from $0.25-0.5$ $\mathrm{mg} / \mathrm{kg}$. For patients with mild to moderate variants of G6PD deficiency, a once-per-week, single $0.75 \mathrm{mg} / \mathrm{kg}$ dose of primaquine over eight weeks is recommended, although careful monitoring for hemolysis is also recommended. Unfortunately, none of these regimens is operationally easy to implement. In Brazil and Peru, this has been partially addressed by using a higher-dose, shorter-length primaquine regimen. Tafenoquine as a single-dose radical cure therapy would represent a significant advance in P. vivax therapy. However, a major barrier to widescale adoption of both of these drugs is toxicity in people with G6PD deficiency. While all people exposed to primaquine experience some drop in haemoglobin concentrations [17], people with G6PD deficiency are more likely to experience severe haemolysis, leading to severe haemolytic anaemia and, potentially, death. Despite the availability of primaquine since the 1950 s, safety data are scarce.

WHO, confronted with emerging resistance to artemisinin and renewed political will to eliminate malaria in many regions of the world, recently released recommendations to administer low doses of primaquine to all patients presenting with falciparum malaria in those settings $[18,19]$. Based on available data, the new recommended doses are suggested to be low enough to be safe even for G6PD-deficient patients but high enough to have a gametocytocidal effect and block transmission [19,20]. However, before these recommendations can be implemented, primaquine will need to be registered in many countries for this use. Uganda and other countries are conducting studies to better understand local prevalence 
and types of G6PD deficiency, even within the context of these low doses [2,21].

User requirements and target product profile for G6PD tests The possible role of G6PD tests within the context of using primaquine for blocking transmission has been discussed elsewhere $[2,18,19]$. The Bangkok workshop focused on diagnostic tests for G6PD deficiency in P. vivax case management. One breakout session was dedicated to identifying how a patient typically presents with P. vivax infection, how the patient is managed in this scenario, and what type of diagnostic test would be required to support case management. Scenarios were created for Cambodia, India, Myanmar, and Thailand. At least one national malaria control programme representative participated, along with researchers with experience in each country. The different country groups were asked to select a target patient profile, regardless of whether this type of patient carried the highest burden of disease.
In all four settings, it was determined that the target patient would benefit most from a point-of-care G6PD test. There was robust debate over who would use the test and exactly how far into the periphery of the health system the test should go, depending on how complex the treatment algorithm would be. For many cases, based on the fact that many users would have access to a mobile phone and, therefore, some access to electric power, participants felt that some type of automated reader, while not ideal, may be acceptable. While a reader may restrict some access, it can also confer benefits, such as remote monitoring, and it could possibly support some means of recordkeeping [22]. Part of the Bangkok discussion revolved around how often a G6PD test would have to be performed for each individual, and a discussion arose regarding the challenges of record keeping, especially with migrant populations.

Based on this discussion, workshop participants created a generic target product profile (Table 1) [4].

Table 1 Product features of a point-of-care G6PD test in support of radical cure

\begin{tabular}{|c|c|c|c|}
\hline Features & Ideal & Acceptable & Comments \\
\hline Test output & Binary, deficient/normal & Quantitative & $\begin{array}{l}\text { Presumes a consensus definition } \\
\text { of normal that aligns with drug safety }\end{array}$ \\
\hline User & $\begin{array}{l}\text { Village health workers, mobile } \\
\text { malaria workers }\end{array}$ & $\begin{array}{l}\text { District hospital, laboratory } \\
\text { worker }\end{array}$ & $\begin{array}{l}\text { This will be defined by national } \\
\text { malaria control programmes }\end{array}$ \\
\hline Platform & $\begin{array}{l}\text { Point-of-care similar to a } \\
\text { malaria rapid diagnostic test }\end{array}$ & $\begin{array}{l}\text { A disposable device coupled to a } \\
\text { portable, battery-operated device; } \\
\text { sensitivity significantly better than } \\
\text { human eye }\end{array}$ & $\begin{array}{l}\text { A reader would be acceptable if it significantly } \\
\text { improves operational performance }\end{array}$ \\
\hline Specimen type & Capillary blood & Capillary blood & $\begin{array}{l}\text { Tests must be evaluated for performance } \\
\text { with this specimen type }\end{array}$ \\
\hline $\begin{array}{l}\text { Stability } \\
\text { requirements }\end{array}$ & 2 years at $37^{\circ} \mathrm{C}$ & 1 year at $37^{\circ} \mathrm{C}$ & \multirow{2}{*}{$\begin{array}{l}\text { Expect low throughput at clinic level, } \\
\text { so requires small quantities per package } \\
\text { or long shelf life }\end{array}$} \\
\hline Packaging & Maximum 25 tests per kit & Maximum 25 tests per kit & \\
\hline $\begin{array}{l}\text { Operational } \\
\text { temperature range }\end{array}$ & $25-40^{\circ} \mathrm{C}$ & $25-40^{\circ} \mathrm{C}$ & $\begin{array}{l}\text { G6PD enzyme activity is highly temperature } \\
\text { dependent (see Figure 2) }\end{array}$ \\
\hline $\begin{array}{l}\text { Operational } \\
\text { humidity range }\end{array}$ & $40-90 \%$ & $40-90 \%$ & None. \\
\hline Time to result & $<10$ minutes & $<30$ minutes & $\begin{array}{l}\text { Availability of the test result should be } \\
\text { aligned with malaria diagnosis and } \\
\text { treatment work flow }\end{array}$ \\
\hline Read window & $>1$ hour & 10 minutes & $\begin{array}{l}\text { Ideally, the test result can be read at any } \\
\text { time point after the initial time to result }\end{array}$ \\
\hline Sensitivity & $\begin{array}{l}\text { Detects all patients (100\%) with G6PD } \\
\text { activity less than a predetermined cut-off, } \\
\text { at or less than which it is unsafe to prescribe } \\
\text { a particular dosage of an 8-aminoquinoline }\end{array}$ & $\begin{array}{l}>95 \% \text { for patients at or less than } \\
\text { a defined cut-off G6PD activity }\end{array}$ & $\begin{array}{l}\text { For primaquine, where the fluorescent spot } \\
\text { test has been accepted as the standard of } \\
\text { care, a 30-40\% normal G6PD activity cut-off } \\
\text { should be used; for new drugs such as } \\
\text { tafenoquine, the cut-off is likely to be higher }\end{array}$ \\
\hline Specificity & $>95 \%$ & $>70 \%$ & $\begin{array}{l}\text { It is preferable to have some patients with } \\
\text { normal G6PD activity levels classified as } \\
\text { deficient as determined by the Receiver } \\
\text { Operating Curve of a diagnostic test }\end{array}$ \\
\hline Price & $\begin{array}{l}\text { Similar to or less than a malaria } \\
\text { rapid diagnostic test }\end{array}$ & $\begin{array}{l}\text { Similar to or less than a } \\
\text { malaria rapid diagnostic test }\end{array}$ & $\begin{array}{l}\text { G6PD test represents an additional cost over } \\
\text { that of malaria diagnosis and treatment }\end{array}$ \\
\hline
\end{tabular}




\section{G6PD product landscape G6PD activity tests}

A survey of products and reagents available for G6PD deficiency testing shows a surprisingly large number of products in the market (more than 20). Available tests determine the G6PD phenotype and overall G6PD activity in a blood specimen, either by direct measurement or through dyes. The outputs can be quantitative, semiquantitative, or qualitative depending on the platform and assay. Different types of G6PD phenotype assays have recently been reviewed $[4,6,23,24]$.

When workshop attendees were asked which G6PD tests they use, more than 15 products were mentioned, spanning at least three assay platforms. Perhaps the most consolidated G6PD products are those used for newborn screening, which often have high-complexity and sometimes high-throughput platforms [25]. These tests are used in Southeast Asia in national newborn screening due to the high G6PD deficiency prevalence in the region and the risk for infants to develop severe hyperbilirubinaemia, acute bilirubin encephalopathy, and kernicterus [26,27].

Quantitative tests for G6PD activity are considered the gold standard. Yet the predominant standard of care for G6PD deficiency screening is a qualitative test, the fluorescent spot test, for which there are several commercial kits as well as homebrew assays (assays assembled in the testing laboratory). Beyond those, the wide range of products in the market offer different levels of complexity, usability, and performance. Some of these tests have been developed on platforms more suitable for use within the context of malaria case management [28-33]. Overall, with few exceptions [34], there is a paucity of published data that compare G6PD deficiency determination across platforms, and most products on the market have not been evaluated independently.

\section{G6PD genotype tests}

G6PD genotype tests characterize the genetic contribution to the G6PD phenotype in a patient. There are several levels at which these tests can be performed, with different degrees of accuracy or resolution. Gel electrophoresis or cytochemical staining can indirectly determine zygosity in females based on whether two G6PD proteins with distinct electrophoretic characteristics or two red cell populations with distinct G6PD activity profiles are observed respectively [35-37]. These are predominantly laboratory-based or homebrew assays. More typically, genotyping is performed through polymerase chain reaction (PCR)-based single nucleotide polymorphism (SNP) analysis, and some commercial primer sets are available to determine the genotype through multiplexed PCR. Because not all SNPs can be multiplexed into a single
PCR reaction, different panels have been developed based on population prevalence. This genotyping approach is limited to identifying known genotypes and results in severely biased genotype data. Consequently, when both genotyping and phenotyping have been performed on the same patients, the correlation has been mixed $[9,38,39]$. This is possibly due to different populations experiencing different degrees of polymorphism in this gene and to the severity in G6PD deficiency conferred by the prevalent genotype in a given population.

Sequencing provides the most deterministic G6PD gene characterization, but the G6PD gene-with its 12 introns and 13 exons spanning $18.5 \mathrm{~Kb}$ base pairs-is an awkward gene to sequence economically. Given the new sequencing technologies now available, investments should be made in developing multiplexed sequencing assays that look at a range of haemoglobinopathies. Research ethics and consent implications for this type of multiplexed sequencing assay need to be openly investigated and discussed.

\section{Technical knowledge gaps}

To develop G6PD tests that will inform patient management with 8-aminoquinolines, many questions remain to be answered, both in terms of the G6PD assay itself and the clinical context. Most of these questions revolve around two fundamental issues: (1) defining normal G6PD activity, and (2) defining a G6PD activity cut-off greater than which it is safe to administer a drug at a given.

\section{Defining normal G6PD activity}

For the purpose of evaluating diagnostic tests for G6PD deficiency a standard approach for defining an absolute value for normal G6PD activity in a population is required. Ambiguity in how this value is calculated presents practical difficulties in evaluating the performance of G6PD tests, and particularly that of qualitative tests. For qualitative tests, performance will depend on the boundary, or the cut-off point, between normal and deficiency. Typically, G6PD deficiency has been defined as a percentage of normal G6PD activity. In practice, there are almost as many definitions of normal activity as there are publications for evaluating G6PD diagnostic tests [30-33,40,41].

\section{Defining the boundary between normal G6PD activity and G6PD deficiency}

Further complicating the issue, there is a paucity of data to correlate definitions for different degrees of G6PD deficiency with risk after exposure to an 8-aminoquinoline challenge $[6,42]$. This remains a major knowledge gap in understanding G6PD deficiency and the risk of exposure to primaquine and tafenoquine. While it is known that G6PD genotypes differentially impact the response to 
primaquine, this knowledge is restricted to only a few of the known G6PD deficiency traits [43,44]. Additionally, acceptable G6PD activity levels for primaquine administration have been defined by the most predominantly used G6PD assay-the fluorescent spot test. This test, by nature of its assay conditions, defines "deficient" at approximately $10 \%$ to $30 \%$ of normal G6PD activity. As a result, people with severe G6PD deficiency are predominantly excluded from primaquine treatment, whereas most people with mild G6PD activity and most heterozygous women are treated with primaquine. Anecdotally, "this works," but there are no supportive, published data.

If the goal is to expose only patients with normal G6PD activity to 8-aminoquinolines, then the cut-off G6PD activity level would have to be in range of $60 \%$ to $70 \%$ of normal values, as per the WHO classification. This would also exclude a significant portion of heterozygous women, at least those in whom there are a significant proportion of G6PD-deficient red blood cells.

These two arbitrary definitions or cut-offs have an immense impact on performance requirements for a G6PD test. This is a consequence of the distribution of G6PD activities across a population (Figure 1). Typically, G6PD activity in a population is bimodal, with a minor group of individuals clustered around $10 \%$ or less G6PD activity and most clustered in the $60 \%$ to $150 \%$ range. The $10 \%$ to $30 \%$ G6PD activity cut-off considered acceptable for primaquine is essentially defined by the fluorescent spot test, a qualitative test for G6PD activity. Thus, developing additional qualitative G6PD tests with similar performance is presumably feasible, though there is a need for improved understanding of the impact of different genotypes on the performance of such qualitative tests against a quantitative test.

By contrast, developing a qualitative G6PD test that accurately excludes patients with less than $60 \%$ or $70 \%$

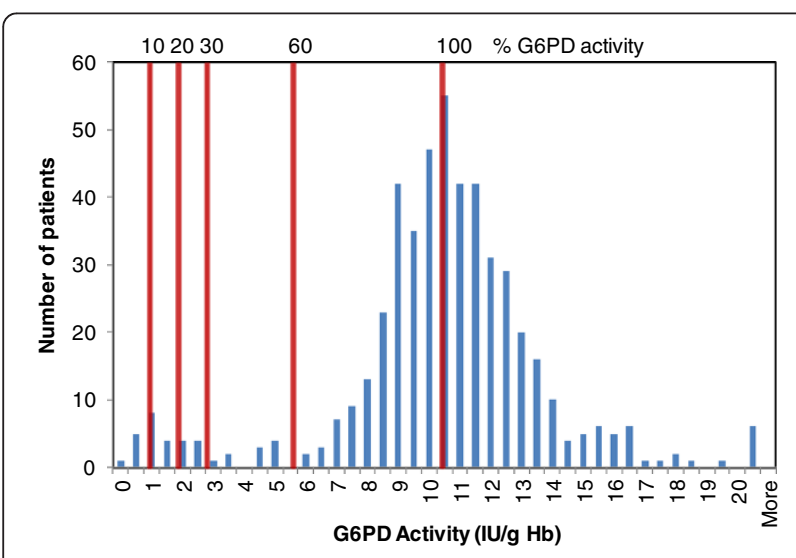

Figure 1 Histogram of G6PD activity for a population described in Table 3; $10 \%, 20 \%, 30 \%$, and $60 \%$ of the adjusted normal G6PD activity for this population are indicated on the graph.
G6PD activity is likely to be extremely challenging, given the noise-to-signal levels that are likely to exist at this level of activity. A test with discriminatory capabilities in the $60 \%$ to $70 \%$ cut-off range is likely to require an underlying quantitative or semi-quantitative platform.

Unfortunately, published G6PD test evaluations use inconsistent definitions of normal G6PD activity and also define test sensitivity and specificity based on different cut-off points or degrees of G6PD deficiency. Thus, it is challenging to understand what a qualitative G6PD test defines as normal or deficient and to compare performance claims between publications. Consistent standards for evaluating G6PD tests are sorely needed.

\section{Factors affecting G6PD test performance}

Several factors can influence the performance of a G6PD test and its ability to correctly classify a patient as either normal or deficient, starting with the cut-off definition as previously described. These include biological conditions such as concomitant haemoglobinopathies, recent haemolytic events that leave a patient with a relatively high proportion of young cells with high G6PD activity that can produce a false normal result, and high leukocyte counts that also lead to a false normal G6PD result. For some of these factors-including a recent malaria infection or other pathological events-it may be possible to predict their effects on a G6PD activity-based assay, but it is still difficult to know how they may affect the risk of an adverse reaction to 8-aminoquinoline exposure. Understanding the impact of haemoglobinopathies and recent haemolytic events on a patient's response to 8-aminoquinolines and the test performance are critical research questions [4].

Because they are enzyme activity tests, the G6PD assays are particularly sensitive to specimen handling and reaction conditions. Specimen integrity is highly sensitive to handling and storage conditions. Acceptable specimen storage conditions for whole blood is up to 14 days at $4^{\circ} \mathrm{C}$ and for dried blood spots up to 10 days at $4^{\circ} \mathrm{C}$ or $48-72$ hours at room temperature $[28,31,45]$. Substrate concentrations and fluctuations in assay temperature influence the enzyme turnover rate. A change of approximately 1 degree in temperature produces a change of $6 \%$ in enzyme activity (Figure 2A) [13]. The effect of temperature on G6PD activity values can be accounted for quite effectively by temperature correction factors (Figure 2B). However, in the case of qualitative tests, this may lead to misclassifying deficient specimens as normal if a test is used outside the validated working temperature range (Figure $2 \mathrm{C}$ ). The combined impact of compromises in specimen collection and operational reaction conditions on the performance of the test in typical malaria treatment settings may result in a wider gap between operational performance of a G6PD test and analytical performance of the test determined under controlled laboratory conditions. 

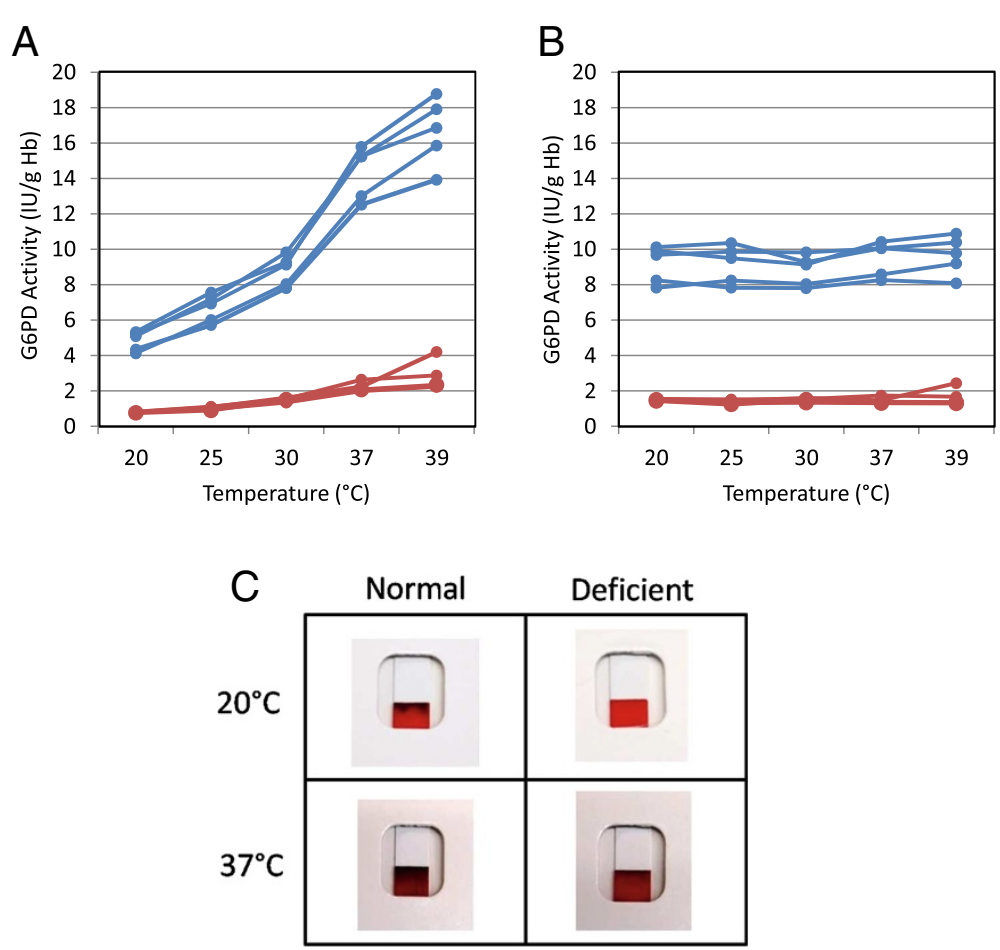

Figure 2 Impact of temperature on G6PD activity-based tests. A. Impact of temperature on quantitative determinations of G6PD activity for five normal and four deficient G6PD samples. B. Normalization of G6PD activity to $30^{\circ} \mathrm{C}$ through application of the temperature correction factor (Table 2) to values in A. C. Impact of temperature on outputs from a qualitative G6PD test. The deficient sample test result at high temperature looks similar to that of a normal sample at low temperature. Note: the temperature range used for Figure $2 \mathrm{C}$ is outside the recommended temperature range in the product insert.

The high proportion of mutations leading to G6PD deficiency affect the stability of the enzyme and specifically the dimer interface $[15,46]$. Consequently, the dilution factor to which the specimen is subjected in the final assay is also likely to affect the test result and this effect is potentially variant specific (Table 2). Given that the fluorescent spot test is the current standard of care, it will be important to compare the performance of the fluorescent spot test against a quantitative test in different geographical settings to understand this relationship.

In the case of females with heterozygous G6PD alleles, while many display a phenotype of intermediate or mild G6PD deficiency, it is clear from available data that heterozygous women cannot be accurately identified through G6PD enzyme activity assays.
Proposed principles for evaluating diagnostic tests

G6PD tests play a critical safety role in strategies involving radical cure of $\mathrm{P}$. vivax malaria and there is demand for evaluation of the tests. Defining pragmatic guidelines for the evaluation of G6PD tests will be critical to allow comparison of findings between evaluation studies. Below, one approach which would allow meta-analysis of data across sites is suggested. A quantitative test for the gold standard is recommended, but it is also recognized that it is not trivial to implement a G6PD quantitative assay in many field sites.

\section{Study population description}

Minimal study population characteristics that need to be assessed for any field evaluation include the proportion of G6PD-deficient cases in the study population, mean

Table 2 Factor by which blood is diluted in the final G6PD activity assay as performed on different G6PD deficiency diagnostic platforms

\begin{tabular}{|c|c|c|c|c|c|}
\hline & $\begin{array}{l}\text { Trinity biotech G-6- } \\
\text { PDH quantitative test }\end{array}$ & $\begin{array}{l}\text { R\&D diagnostics Ltd } \\
\text { quantitative test }\end{array}$ & $\begin{array}{l}\text { Trinity biotech G-6-PDH } \\
\text { fluorescent spot test }\end{array}$ & $\begin{array}{l}\text { Alere BinaxNOW } \\
\text { Malaria test }\end{array}$ & $\begin{array}{l}\text { Access Bio CareStart }{ }^{\mathrm{TM}} \text { G6PD } \\
\text { deficiency screening test }\end{array}$ \\
\hline $\begin{array}{l}\text { Initial specimen } \\
\text { volume }\end{array}$ & $10 \mathrm{ul}$ & $5 \mu l$ & $10 \mu \mathrm{l}$ & $10 \mu \mathrm{l}$ & $3 \mu l$ \\
\hline Dilution factor & 301 & 80 & 21 & 8 & 41 \\
\hline
\end{tabular}

G-6-PDH: glucose-6-phosphate dehydrogenase. 
and median G6PD activity of the study population, and the adjusted male median activity (see below and Table 3 ). Mean and median values of G6PD activity need to be stratified by gender and adjusted for ambient temperature and the proportion of G6PD-deficient study participants (see below).

If purposive patient recruitment results in inclusion of more G6PD-deficient patients than the local prevalence, mean and median G6PD activity levels also should be provided for the normal males in the study.

\section{Definitions}

The definitions provided below are for performance comparison of a qualitative G6PD test to a quantitative G6PD test.

\section{Male median}

To minimize the impact of heterozygosity on the definition of G6PD activity, researchers should use the median value of G6PD activity for the entire male population in the study. If purposive or biased recruitment were used for an evaluation, the median G6PD value of the G6PD-normal male recruited for the study should be used as the definition of normal. Otherwise, an adjusted male median calculated as described below should be used.

\section{Adjusted median (100\% G6PD activity)}

To account for variability in prevalence of G6PD deficiency in a given study population, an adjusted median value is calculated for which males with severe G6PD deficiency (activity less than 10\% normal) have been excluded. This is accomplished by:

1. Exclusion of all males with G6PD activity equal to or less than $10 \%$ of the male median.

2. Determination of a new median G6PD activity. This is the "adjusted median," which can be used as the $100 \%$ G6PD activity value from which cut-off levels are defined.

Table 3 Proposed reference values to describe the G6PD activity profile for a study population

\begin{tabular}{lllll}
\hline Reference values & Total & Female & Male & Adjusted male \\
\hline Number of cases & 500 & 282 & 218 & 203 \\
Mean $(95 \% \mathrm{Cl}) \mathrm{U} / \mathrm{g} \mathrm{Hb}$ & 10.23 & 10.38 & 10.03 & 10.72 \\
Standard deviation & 2.28 & 2.10 & 2.52 & 1.97 \\
Median (95\% Cl) U/g Hb & 10.33 & 10.31 & 10.34 & 10.70 \\
Range & $0-32.25$ & $0.38-32.25$ & $0-24.32$ & $1.50-24.32$
\end{tabular}

$\mathrm{Cl}$ : confidence interval; $\mathrm{Hb}$ : haemoglobin; $\mathrm{U}$ : International Unit. The table is populated with an example data set randomly selected from a true set of quantitative G6PD test results for a population (data kindly provided by Ari Satyagraha).

\section{Cut-off}

The percentage of adjusted median at or less than which a patient is classified as positive (G6PD deficient). Samples with G6PD activity greater than the cut-off are considered negative.

\section{True positive (TP)}

A sample correctly classified by the diagnostic test under evaluation as having G6PD activity at or less than the cut-off.

\section{False positive (FP)}

A sample incorrectly classified by the diagnostic test under evaluation as having G6PD activity at or less than the cut-off.

\section{True negative (TN)}

A sample correctly classified by the diagnostic test under evaluation as having G6PD activity greater than the cut-off.

\section{False negative (FN)}

A sample incorrectly classified by the diagnostic test under evaluation as having G6PD activity greater than the cut-off.

\section{Range of patients that should be excluded from treatment with 8-aminoquinolines}

All patients with G6PD activity less than or equal to the cut-off as determined by the gold standard test (TP + FN).

Range of patients with levels of G6PD activity safe to receive treatment with 8 -aminoquinolines

All patients with G6PD activity greater than the cut-off $(\mathrm{TN}+\mathrm{FP})$.

\section{Sensitivity}

Probability that the test will detect a person with G6PD deficiency.

$$
\text { Sensitivity }=\frac{T P}{T P+F N}
$$

\section{Specificity}

Probability that the test will detect a person with G6PDnormal activity.

$$
\text { Specificity }=\frac{T N}{T N+F P}
$$

\section{Positive predictive value}

Probability that the patient is G6PD deficient when the diagnostic test under evaluation yields a positive result. 


$$
\text { Positive predictive value }=\frac{T P}{T P+F P}
$$

\section{Negative predictive value}

Probability that the patient has normal G6PD activity when the diagnostic test yields a negative result.

$$
\text { Negative predictive value }=\frac{T N}{T N+F N}
$$

\section{Gold standard testing}

An established quantitative G6PD test should be implemented as the gold standard test for which 100\% G6PD activity and the cut-offs are defined. The quality of the quantitative test should be controlled either through commercially available artificial controls or through samples with known G6PD activity levels. Ideally, this is performed under strict temperature control using venous blood (acid-citrate-dextrose or EDTA anticoagulant). If strict temperature control cannot be applied, the temperatures at which the assays were performed should be recorded and then standardized to G6PD activity at $30^{\circ} \mathrm{C}$ according to temperature correction factors. Some product inserts, such as those for the Trinity Biotech. quantitative test, provide temperature correction factors (Table 4).

\section{Sample size calculations for diagnostic test evaluation}

The sample size for evaluations of G6PD tests is driven by the expected performance of the diagnostic test against the predicate gold standard, the local G6PD deficiency prevalence, and the desired accuracy for

\begin{tabular}{|c|c|c|c|}
\hline $\begin{array}{l}\text { Cuvette } \\
\text { temperature }\left({ }^{\circ} \mathrm{C}\right)\end{array}$ & $\begin{array}{c}\text { Temperature } \\
\text { correction factor }\end{array}$ & $\begin{array}{c}\text { Cuvette } \\
\text { temperature }\left({ }^{\circ} \mathrm{C}\right)\end{array}$ & $\begin{array}{l}\text { Temperature } \\
\text { correction factor }\end{array}$ \\
\hline 20 & 1.90 & 30 & 1.00 \\
\hline 21 & 1.76 & 31 & 0.94 \\
\hline 22 & 1.66 & 32 & 0.89 \\
\hline 23 & 1.55 & 33 & 0.83 \\
\hline 24 & 1.46 & 34 & 0.78 \\
\hline 25 & 1.37 & 35 & 0.74 \\
\hline 26 & 1.28 & 36 & 0.70 \\
\hline 27 & 1.20 & 37 & 0.66 \\
\hline 28 & 1.13 & 38 & 0.62 \\
\hline 29 & 1.06 & 39 & 0.58 \\
\hline
\end{tabular}
resulting sensitivity and specificity claims (width of $95 \%$ confidence intervals around estimates of sensitivity and specificity). Given the relatively low G6PD deficiency prevalence in most populations worldwide, the sample size is primarily driven by the prevalence and desired accuracy for the evaluation results. Table 5 shows sample calculations for a set of expected test sensitivities over two accuracy constraints and for three G6PD deficiency prevalence rates. In the absence of an appropriate sample size, the statistical power of the study is compromised and the implied uncertainty of the study must be clearly explained.

\section{G6PD test performance criteria}

In the absence of a more complete understanding of the relationship between risk of haemolysis and level of G6PD deficiency, as well as local G6PD reference values, it is impossible to define a clear normal/deficient G6PD activity cut-off that is consistent and clinically relevant as pertaining to safety and treatment with an 8-aminoquinoline. As a consequence, test performance criteria should be provided for a range of G6PD activity. Percentage of median activity is proposed in order to account for inter-assay and inter-laboratory variability in absolute G6PD activity values. The minimum proposed degrees of deficiency are based on WHO classifications and commonly used ranges: $10 \%, 20 \%, 30 \%$, and $60 \%$ of the normal male or adjusted median G6PD activity. Absolute cut-off values (in $\mathrm{U} / \mathrm{g} \mathrm{Hb}$ ) and sensitivity, specificity, positive predictive value, and negative predictive value should be determined for this range of degrees of G6PD deficiency. Example performance data for the evaluation of a putative G6PD test are described in Tables 3 and 6; the cut-offs are shown in Figure 1.

\section{Regulatory considerations for G6PD testing}

The first step toward regulating the quality of G6PD tests will be to define evaluation standards for this class of diagnostic tests. In many countries where G6PD tests are needed to support P. vivax case management, regulatory mechanisms for diagnostic tests are absent, weak, or in transition. In the absence of national guidelines, some countries default to CE mark and US Food and Drug Administration (FDA) approval. Currently, the BinaxNOW ${ }^{\circledR}$ G6PD test marketed in the United States has obtained FDA approval under 510(k) clearance. Most G6PD tests on the market have at best obtained only CE mark approval.

There is a concern that without clear guidelines for G6PD testing performance criteria, point-of-care G6PD testing will follow a similar route as the malaria rapid diagnostic tests (RDTs), albeit to a smaller scale, wherein a large number of products with varying degrees of quality control and performance entered the market. Variability in RDT quality produced distrust of the product generally, 
Table 5 Sample size calculations for evaluation of G6PD diagnostic tests for radical cure

\begin{tabular}{|c|c|c|c|c|c|c|}
\hline \multirow{2}{*}{$\begin{array}{l}\text { Expected } \\
\text { sensitivity }\end{array}$} & \multirow{2}{*}{$\begin{array}{l}\text { Desired } \\
\text { width of } \mathrm{Cl}\end{array}$} & \multirow{2}{*}{$\begin{array}{l}\text { Confidence } \\
\text { level }\end{array}$} & \multirow{2}{*}{$\begin{array}{c}\text { Number of } \\
\text { disease cases needed }\end{array}$} & \multicolumn{3}{|c|}{ Sample size } \\
\hline & & & & Prevalence rate $10 \%$ & Prevalence rate $15 \%$ & Prevalence rate $20 \%$ \\
\hline 0.8 & 0.06 & 0.95 & 715 & 7150 & 4767 & 3575 \\
\hline 0.8 & 0.1 & 0.95 & 264 & 2640 & 1760 & 1320 \\
\hline 0.9 & 0.06 & 0.95 & 417 & 4170 & 2780 & 2085 \\
\hline 0.9 & 0.1 & 0.95 & 158 & 1580 & 1053 & 790 \\
\hline 0.95 & 0.06 & 0.95 & 238 & 2380 & 1587 & 1190 \\
\hline 0.95 & 0.1 & 0.95 & 94 & 940 & 627 & 470 \\
\hline 0.96 & 0.06 & 0.95 & 200 & 2000 & 1333 & 1000 \\
\hline 0.96 & 0.1 & 0.95 & 81 & 810 & 540 & 405 \\
\hline 0.97 & 0.06 & 0.95 & 161 & 1610 & 1073 & 805 \\
\hline 0.97 & 0.1 & 0.95 & 68 & 680 & 453 & 340 \\
\hline 0.98 & 0.06 & 0.95 & 123 & 1230 & 820 & 615 \\
\hline 0.98 & 0.1 & 0.95 & 55 & 550 & 367 & 275 \\
\hline 0.99 & 0.06 & 0.95 & 87 & 870 & 580 & 435 \\
\hline 0.99 & 0.1 & 0.95 & 44 & 440 & 293 & 220 \\
\hline
\end{tabular}

Cl: confidence interval.

and slowed uptake of RDT technology. For G6PD tests, prevention, rather than remediation, of such a problem will likely be less costly for the malaria control and elimination community.

\section{Operational considerations for G6PD testing}

Although participants in the workshop's use case scenario session unanimously identified a point-of-care G6PD test as the ideal product profile to support P. vivax case management with 8-aminoquinolines, it does not necessarily follow that:

1. This product profile has a large market demand. The workshop attendees were primarily focused on malaria patients who are the hardest to reach rather than on the largest number of people at risk.
2. This is the best solution for all use cases. As neonatal screening programmes improve in many countries, a more cost-effective approach may be to improve information management systems such that the G6PD status of a patient is more readily available and the need for repeat testing can be minimized.

In Malaysia, neonatal G6PD screening is routinely performed, and G6PD records accompany the patient. In a case where a patient's status is not known, a fluorescent spot test is done, and primaquine is administered based on G6PD status. In contrast, in the Philippines, neonatal screening is supposed to be routinely done but is not universally available, especially to remote and indigenous populations most at risk of malaria infection.

Table 6 Performance results for a putative qualitative diagnostic test modeled against the quantitative results described in Table 3

\begin{tabular}{|c|c|c|c|c|}
\hline & $10 \%$ cut-off & $20 \%$ cut-off & $30 \%$ cut-off & $60 \%$ cut-off \\
\hline Cutoff value $(\mathrm{U} / \mathrm{g} \mathrm{Hb})$ & 1.07 & 2.14 & 3.21 & 6.42 \\
\hline Number of samples with G6PD levels less than cut-off (percentage) & $14(2.8)$ & $24(4.8)$ & $28(5.6)$ & $41(8.2)$ \\
\hline \multirow[t]{2}{*}{ Sensitivity percentage $(95 \% \mathrm{Cl})$} & 100 & 95.8 & 89.3 & 68.3 \\
\hline & $(73-100)$ & $(77-100)$ & $(71-97)$ & $(52-81)$ \\
\hline \multirow[t]{2}{*}{ Specificity percentage (95\% Cl) } & 97.1 & 98.9 & 99.4 & 100 \\
\hline & $(95-98)$ & $(97-100)$ & $(98-100)$ & $(99-100)$ \\
\hline \multirow[t]{2}{*}{ Positive predictive value percentage ( $95 \% \mathrm{Cl}$ ) } & 0.5 & 0.82 & 0.89 & 1.00 \\
\hline & $(0.31-0.69)$ & $(0.62-0.93)$ & $(0.71-0.97)$ & $(0.84-1.00)$ \\
\hline \multirow[t]{2}{*}{ Negative predictive value percentage ( $95 \% \mathrm{Cl})$} & 1.00 & 1.00 & 0.99 & 0.97 \\
\hline & $(0.99-1.00)$ & $(0.99-1.00)$ & $(0.98-1.00)$ & $(0.95-0.98)$ \\
\hline
\end{tabular}

Cl: confidence interval; $H b$ : haemoglobin; U: International Unit. 
The goal of operational research around G6PD deficiency testing and radical cure with 8-aminoquinolines should focus on how to ensure that G6PD status information is available at the point of case management for a patient presenting with $P$. vivax infection. This may involve linking drug availability to availability of a pointof-care G6PD test, to medical records, or a combination of the two.

Another challenge with introducing and scaling up new G6PD tests is that there are currently few guidelines for adopting and training end users on G6PD testing and counseling. Also, confirming or evaluating operational effectiveness of a G6PD test in clinical settings, as opposed to analytical performance, will be challenging. Additionally an external quality assurance programme will be required. Cost analysis of different approaches to ensuring safe delivery of 8 -aminoquinolines should take these factors into consideration, as they may significantly influence cost-effectiveness outcomes.

Market studies segmenting where point-of-care G6PD tests are needed in place of more complex assays will be useful for malaria programmes in terms of resource allocation and for suppliers in terms of understanding the true market size. From the pricing perspective, ideally a G6PD test would be available at the price of a malaria RDT or less. For primaquine, given its low cost, a significantly more expensive test will shift the burden of the cost significantly from treatment costs to diagnostic costs and may impact willingness to pay. Potentially more expensive drugs may tolerate higher prices. From a programme perspective, cost-effectiveness studies should be designed to identify boundaries of these costs.

\section{Conclusions}

From a public health perspective, uncertainty remains on whether G6PD testing deficiency status does not need to be taken into account for primaquine-based radical cure in some populations, as reflected in the current WHO guidelines. However, from a patient management perspective, where the individual risk/benefit ratio dictates optimal treatment, knowing the G6PD status of the patient is a prerequisite for prescribing an 8 -aminoquinoline-based drug.

Although many questions remain regarding G6PD deficiency and the risk of drug-related adverse events, this should not hinder efforts to evaluate and adopt G6PD tests in support of radical cure. G6PD testing represents an additional cost for malaria treatment and unnecessary G6PD testing should be minimized. Health systems, health management information systems, careseeking practices, and malaria epidemiology will determine the best way to ensure knowledge of G6PD status for people who have access to 8 -aminoquinoline radical cure regimens. While an approach that includes population screening and effective recordkeeping is attractive for the long term, it is clear that point-of-care G6PD testing will be required to meet immediate needs, given that the populations most at risk of $\mathrm{P}$. vivax infection are typically those at the periphery of health care systems and the hardest to reach. In these scenarios, significant operational research will be required to understand how to supply these tests, who the end users should be, how to link the availability of the tests with that of the drugs, and how to implement a recordkeeping system that minimizes the need for repeat testing of individual patients.

A prerequisite to introducing G6PD testing is the availability of high-quality G6PD tests with product profiles that are compatible with end-use cases. Establishing pragmatic and consistent criteria for evaluation of tests should be a high priority. The development and evaluation of new G6PD tests can benefit from the availability of specimen panels [47]. Because factors unique to local populations may affect the performance of G6PD tests, another priority should be to understand the impact of geographical and genetic diversity on the performance of these tests.

\section{Abbreviations}

Cl: Confidence interval; FDA: US Food and drug administration; FN: False negative; FP: False positive; G6PD/G-6-PDH: Glucose-6-phosphate dehydrogenase; Hb: Haemoglobin; PCR: Polymerase chain reaction; RDT: Rapid diagnostic test; SNP: Single nucleotide polymorphism; TN: True negative; TP: True positive; U: International unit; WHO: World health organization.

\section{Competing interests}

The authors declare that they have no competing interests.

\section{Authors' contributions}

GJD wrote the first draft of the manuscript. All authors contributed to the content, read and approved the final manuscript. LSV is a staff member of the World Health Organization. The author alone is responsible for the views expressed in this publication and they do not necessarily represent the decisions or policies of the World Health Organization.

\section{Acknowledgments}

The authors would like to thank Molly Boettcher and Amanda Vilbrandt for organization and management of meeting logistics, and John Ballenot and Scott Wittet for editorial revision of the manuscript. This publication is based on research funded by the Bill \& Melinda Gates Foundation. The findings and conclusions contained within are those of the authors and do not necessarily reflect positions or policies of their organizations or the Bill \& Melinda Gates Foundation

A report by the G6PD Diagnostics for Radical Cure Discussion Group. Bangkok Meeting Report October 4th and 5th 2012.

\section{Author details}

'PATH, 2201 Westlake Avenue, Suite 200, Seattle, WA 98121, USA. ${ }^{2}$ Eijkman Institute for Molecular Biology, Jakarta, Indonesia. ${ }^{3}$ National Institute of Malaria Research, New Delhi, India. ${ }^{4}$ Eijkman- Oxford Clinical Research Unit, Jakarta, Indonesia. ${ }^{5}$ Shoklo Malaria Research Unit, Mae Sot, Thailand. ${ }^{6}$ GlaxoSmithKline, Stockley Park, Uxbridge, UK. ${ }^{7}$ Australian Army Malaria Institute, Enoggera, Australia. ${ }^{8}$ Bill \& Melinda Gates Foundation, Seattle, USA. ${ }^{9}$ London School of Hygiene and Tropical Medicine, London, UK. ${ }^{10}$ President's Malaria Initiative, Greater Mekong Subregion, Bangkok, Thailand. ${ }^{11}$ Centers for Disease Control and Prevention; Global Health Group, University of California, San Francisco, USA. ${ }^{12}$ University of the State of Amazonas, Manaus, Brazil. ${ }^{13}$ Institut Pasteur du Cambodge, Phnom Penh, Cambodia. ${ }^{14}$ Mahidol Oxford Research Unit, Bangkok, Thailand. ${ }^{15}$ Chulalongkorn University, Bangkok, 
Thailand. ${ }^{16}$ Department of Medical Research, Lower Myanmar, Yangon, Myanmar. ${ }^{17}$ Bureau of Vector Borne Diseases, Bangkok, Thailand. ${ }^{18}$ PATH, Bangkok, Thailand. ${ }^{19}$ Malaria Consortium, Phnom Penh, Cambodia. ${ }^{20}$ Thailand Ministry of Public Health, Bangkok, Thailand. ${ }^{21}$ National Malaria Control Programme, Phnom Penh, Cambodia. ${ }^{22}$ WHO/WPRO, Manila, Philippines. ${ }^{23}$ Menzies School of Health Research, Darwin, Australia.

Received: 11 September 2013 Accepted: 30 October 2013 Published: 4 November 2013

\section{References}

1. PATH: G6PD Testing in Support of Treatment and Elimination of Malaria Advisory Workshop. [http://sites.path.org/dx/malaria/g6pd/workshop/]

2. Eziefula AC, Gosling R, Hwang J, Hsiang MS, Bousema T, von Seidlein L, Drakeley C: Rationale for short course primaquine in Africa to interrupt malaria transmission. Malar J 2012, 11:360.

3. APMEN: Gaps in glucose-6-phosphate dehydrogenase deficiency detection with regard to the safe clinical deployment of 8-aminoquinoline treatment regimens; 2012 [http://apmen.org/vxwg-2012/]

4. von Seidlein L, Auburn S, Espino F, Shanks D, Cheng Q, McCarthy J, Baird K, Moyes C, Howes R, Menard D, Bancone G, Winasti-Satyahraha A, Vestergaard LS, Green J, Domingo G, Yeung S, Price R: Review of key knowledge gaps in glucose-6-phosphate dehydrogenase deficiency detection with regard to the safe clinical deployment of 8-aminoquinoline treatment regimens: a workshop report. Malar J 2013, 12:112.

5. Cappellini MD, Fiorelli G: Glucose-6-phosphate dehydrogenase deficiency. Lancet 2008, 371:64-74.

6. Howes RE, Battle KE, Satyagraha AW, Baird JK, Hay SI: G6PD deficiency: global distribution, genetic variants and primaquine therapy. Adv Parasitol 2013, 81:133-201.

7. Luzzatto L, Mehta A, Vulliamy TJ: Glucose-6-phosphate dehydrogenase deficiency. In The Metabolic and Molecular Basis of Inherited Disease. Edited by Scriver CR, Beaudet AL, Sly WS, Valle D. New York: McGraw-Hill; 2001:4517-4553.

8. Nkhoma ET, Poole C, Vannappagari V, Hall SA, Beutler E: The global prevalence of glucose-6-phosphate dehydrogenase deficiency: a systematic review and meta-analysis. Blood Cells Mol Dis 2009, 42:267-278.

9. Leslie T, Briceno M, Mayan I, Mohammed N, Klinkenberg E, Sibley CH, Whitty CJ, Rowland M: The impact of phenotypic and genotypic G6PD deficiency on risk of plasmodium vivax infection: a case-control study amongst Afghan refugees in Pakistan. PLoS Med 2010, 25:e1000283.

10. Ruwende $C$, Hill A: Glucose-6-phosphate dehydrogenase deficiency and malaria. J Mol Med 1998, 76:581-588.

11. Santana MS, Monteiro WM, Siqueira AM, Costa MF, Sampaio V, Lacerda MV Alecrim MG: Glucose-6-phosphate dehydrogenase deficient variants are associated with reduced susceptibility to malaria in the Brazilian Amazon. Trans R Soc Trop Med Hyg 2013, 107:301-306.

12. Howes RE, Piel FB, Patil AP, Nyangiri OA, Gething PW, Dewi M, Hogg MM, Battle KE, Padilla CD, Baird JK, Hay SI: G6PD deficiency prevalence and estimates of affected populations in malaria endemic countries: a geostatistical model-based map. PLoS Med 2012, 9:e1001339.

13. World Health Organization: Standardization of procedures for the study of glucose-6-phosphate dehydrogenase. WHO Technical Report Series 1967, 366:1-53.

14. Beutler E, Vulliamy TJ: Hematologically important mutations: glucose-6phosphate dehydrogenase. Blood Cells Mol Dis 2002, 28:93-103.

15. Mason PJ, Bautista JM, Gilsanz F: G6PD deficiency: the genotypephenotype association. Blood Rev 2007, 21:267-283.

16. WHO Working Group: Glucose-6-phosphate dehydrogenase deficiency. Bull World Health Organ 1989, 67:601-611.

17. Kellermeyer RW, Tarlov AR, Brewer GJ, Carson PE, Alving AS: Hemolytic effect of therapeutic drugs: clinical considerations of the primaquine-type hemolysis. JAMA 1962, 180:388-394.

18. WHO Malaria Policy Advisory Committee and Secretariat: Malaria Policy Advisory Committee to the WHO: conclusions and recommendations of September 2012 meeting. Malar J 2012, 11:424.

19. White NJ, Qiao LG, Qi G, Luzzatto L: Rationale for recommending a lower dose of primaquine as a Plasmodium falciparum gametocytocide in populations where G6PD deficiency is common. Malar J 2012, 11:418.

20. Recht J, Ashley EA, White NJ: A review of the safety of 8-aminoquinolines. Bull World Health Organ. in press.
21. Eziefula AC, Staedke SG, Yeung S, Webb E, Kamya M, White NJ, Bousema T, Drakeley C: Study protocol for a randomised controlled double-blinded trial of the dose-dependent efficacy and safety of primaquine for clearance of gametocytes in children with uncomplicated falciparum malaria in Uganda. BMJ Open 2013, 3:002759.

22. Palamountain KM, Baker J, Cowan EP, Essajee S, Mazzola LT, Metzler M, Schito M, Stevens WS, Young GJ, Domingo GJ: Perspectives on introduction and implementation of new point-of-care diagnostic tests. $J$ Infect Dis 2012, 15(Suppl 2):s181-s190.

23. Frank JE: Diagnosis and management of G6PD deficiency. Am Fam Physician 2005, 72:1277-1282.

24. Minucci A, Giardina B, Zuppi C, Capoluongo E: Glucose-6-phosphate dehydrogenase laboratory assay: how, when, and why? IUBMB Life 2009, 61:27-34.

25. Kaplan M, Hammerman C: Neonatal screening for glucose-6-phosphate dehydrogenase deficiency: biochemical versus genetic technologies. Semin Perinatol 2011, 35:155-161.

26. Padilla CD, Therrell BL: Newborn screening in the Asia Pacific region. J Inherit Metab Dis 2007, 30:490-506.

27. Padilla CD, Therrell BL Jr: Consolidating newborn screening efforts in the Asia Pacific region: Networking and shared education. J Community Genet 2012, 3:35-45.

28. De Niz M, Eziefula AC, Othieno L, Mbabazi E, Nabukeera D, Ssemmondo E, Gonahasa S, Tumwebaze P, Diliberto D, Maiteki-Sebuguzi C, Staedke SG, Drakeley C: Tools for mass screening of G6PD deficiency: validation of the WST8/1-methoxy-PMS enzymatic assay in Uganda. Malar J 2013, $12: 210$.

29. Jalloh A, Tantular IS, Pusarawati S, Kawilarang AP, Kerong H, Lin K, Ferreira MU, Matsuoka H, Arai M, Kita K, Kawamoto F: Rapid epidemiologic assessment of glucose-6-phosphate dehydrogenase deficiency in malaria-endemic areas in Southeast Asia using a novel diagnostic kit. Trop Med Int Health 2004, 9:615-623.

30. Kim S, Nguon C, Guillard B, Duong S, Chy S, Sum S, Nhem S, Bouchier C, Tichit M, Christophel E, Taylor WR, Baird KJ, Menard D: Performance of the CareStart G6PD deficiency screening test, a point-of-care diagnostic for primaquine therapy screening. PLoS One 2011, 6:e28357.

31. Kuwahata M, Wijesinghe R, Ho MF, Pelecanos A, Bobogare A, Landry L, Bugora $\mathrm{H}$, Vallely A, McCarthy J: Population screening for glucose-6phosphate dehydrogenase deficiencies in Isabel Province, Solomon Islands, using a modified enzyme assay on filter paper dried bloodspots. Malar J 2010, 9:223.

32. Tantular IS, Iwai K, Lin K, Basuki S, Horie T, Htay HH, Matsuoka H, Marwoto H, Wongsrichanalai C, Dachlan YP, Kojima S, Ishii A, Kawamoto F: Field trials of a rapid test for G6PD deficiency in combination with a rapid diagnosis of malaria. Trop Med Int Health 1999, 4:245-250.

33. Tinley KE, Loughlin AM, Jepson A, Barnett ED: Evaluation of a rapid qualitative enzyme chromatographic test for glucose-6-phosphate dehydrogenase deficiency. Am J Trop Med Hyg 2010, 82:210-214.

34. Wang FL, Boo NY, Ainoon O, Wong MK: Comparison of detection of glucose-6-phosphate dehydrogenase deficiency using fluorescent spot test, enzyme assay and molecular method for prediction of severe neonatal hyperbilirubinaemia. Singapore Med J 2009, 50:62-67.

35. Shah SS, Diakite SA, Traore K, Diakite M, Kwiatkowski DP, Rockett KA, Wellems TE, Fairhurst RM: A novel cytofluorometric assay for the detection and quantification of glucose-6-phosphate dehydrogenase deficiency. Sci Rep 2012, 2:299.

36. van Noorden CJ, Vogels IM, James J, Tas J: A sensitive cytochemical staining method for glucose-6-phosphate dehydrogenase activity in individual erythrocytes. I. Optimalization of the staining procedure. Histochemistry 1982, 75:493-506.

37. van Noorden CJ, Dolbeare F, Aten J: Flow cytofluorometric analysis of enzyme reactions based on quenching of fluorescence by the final reaction product: detection of glucose-6-phosphate dehydrogenase deficiency in human erythrocytes. J Histochem Cytochem 1989, 37:1313-1318.

38. Johnson MK, Clark TD, Njama-Meya D, Rosenthal PJ, Parikh S: Impact of the method of G6PD deficiency assessment on genetic association studies of malaria susceptibility. PLoS One 2009, 4:e7246.

39. Shekalaghe SA, ter Braak R, Daou M, Kavishe R, van den Bijllaardt W, van den Bosch S, Koenderink JB, Luty AJ, Whitty CJ, Drakeley C, Sauerwein RW, Bousema T: In Tanzania, hemolysis after a single dose of primaquine coadministered with an artemisinin is not restricted to glucose-6- 
phosphate dehydrogenase-deficient (G6PD A-) individuals. Antimicrob Agents Chemother 2010, 54:1762-1768.

40. Tantular IS, Kawamoto F: An improved, simple screening method for detection of glucose-6-phosphate dehydrogenase deficiency. Trop Med Int Health 2003, 8:569-574.

41. Nantakomol D, Paul R, Palasuwan A, Day NP, White NJ, Imwong M: Evaluation of the phenotypic test and genetic analysis in the detection of glucose-6-phosphate dehydrogenase deficiency. Malar J 2013, 12:289

42. John GK, Douglas NM, von Seidlein L, Nosten F, Baird JK, White NJ, Price RN: Primaquine radical cure of Plasmodium vivax: a critical review of the literature. Malar J 2012, 11:280

43. Dern RJ, Beutler E, Alving AS: The hemolytic effect of primaquine. II. The natural course of the hemolytic anemia and the mechanism of its self-limited character. J Lab Clin Med 1954, 44:171-176.

44. Piomelli S, Corash LM, Davenport DD, Miraglia J, Amorosi EL: In vivo lability of glucose-6-phosphate dehydrogenase in GdA- and GdMediterranean deficiency. J Clin Invest 1968, 47:940-948.

45. Castro SM, Weber R, Dadalt V, Santos VF, Reclos GJ, Pass KA, Giugliani R: Evaluation of glucose-6-phosphate dehydrogenase stability in blood samples under different collection and storage conditions. Clin Chem 2005, 51:1080-1081.

46. Au SW, Gover S, Lam VM, Adams MJ: Human glucose-6-phosphate dehydrogenase: the crystal structure reveals a structural NADP(+) molecule and provides insights into enzyme deficiency. Structure 2000, 8:293-303.

47. Kahn M, LaRue N, Bansil P, Kalnoky M, McGray S, Domingo GJ: Cryopreservation of glucose-6-phosphate dehydrogenase activity inside red blood cells: developing a specimen repository in support of development and evaluation of glucose-6-phosphate dehydrogenase deficiency tests. Malar J 2013, 12:286.

doi:10.1186/1475-2875-12-391

Cite this article as: Domingo et al:: G6PD testing in support of treatment and elimination of malaria: recommendations for evaluation of G6PD tests. Malaria Journal 2013 12:391.

\section{Submit your next manuscript to BioMed Central and take full advantage of:}

- Convenient online submission

- Thorough peer review

- No space constraints or color figure charges

- Immediate publication on acceptance

- Inclusion in PubMed, CAS, Scopus and Google Scholar

- Research which is freely available for redistribution 